\section{Gender gap in rheumatology: speaker representation at annual conferences}

Adami et al's report of gender disparities in the first authorship of rheumatology guidelines was very interesting to read. ${ }^{1}$ The authors highlight a fundamental issue: the existence of a gender gap - that is, proportionately more male than female physicians-within the authorship ranks in rheumatology. We had thought that it would be intriguing to investigate whether this difference permeates at the national conference level as well. Recent studies have quantified the gender gap among speakers at academic conferences in other specialties. The most extensive study of 181 medical conferences held in North America over the course of a decade (2007-2017) found an increase in the proportion of female speakers from $25 \%$ to $34 \%$ over time, and the under-representation of women to be more marked at surgical compared with medical conferences. ${ }^{2}$

Our goal was to describe the proportion of female representation among speakers and moderators at the American College of Rheumatology (ACR) meetings in 2017 and 2018. Using the ACR Session Tracker programme for these 2 years, we determined the proportion of women for each speaker or moderator slot. We further categorised by basic versus clinical science presentation and by type of session (premeeting, ACR general session, Association of Rheumatology Health Professionals (AHRP) general session, abstracts, workshop, study group or Meet the Professor).

Overall, the proportion of combined female speakers and moderators was $42.8 \%$ in 2017 and $47.0 \%$ in 2018. The representation of female speakers increased from 2017 to 2018 by $4.2 \%$, which in a conference of approximately 1100 presenters (total presenters at the 2018 conference) amounts to 46.2 persons. There was a higher proportion of female speakers in

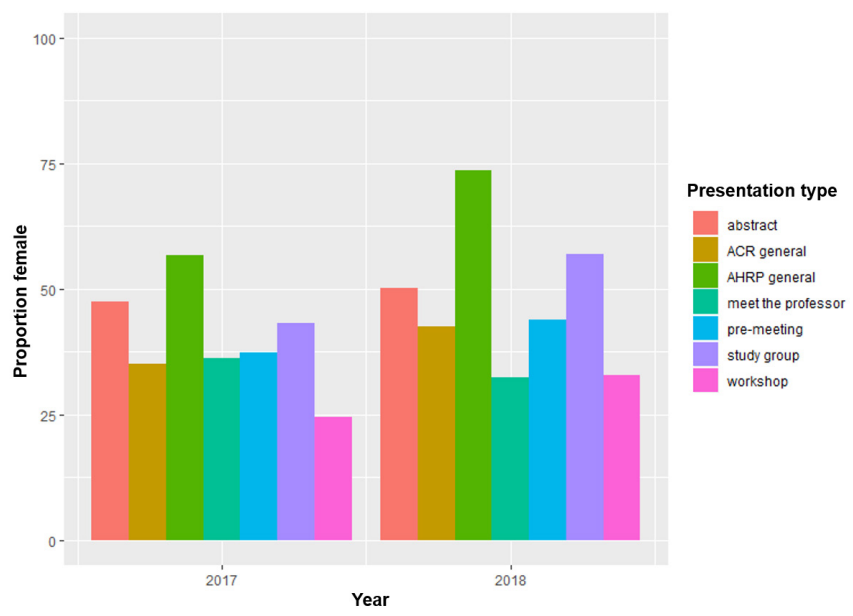

Figure 1 Proportion of female speakers at ACR, by year and presentation type. ACR, American College of Rheumatology; AHRP, Association of Rheumatology Health Professionals. the clinical than in the basic science presentations (mean $45.8 \%$ vs $40.5 \%$ ). By session type, the AHRP sessions had the highest proportion of female representation (mean 65.3\%) while Meet the Professor and workshops had the lowest $34.4 \%$ and $28.7 \%$, respectively) (figure 1 ).

We found that the mean overall proportion of female speakers and moderators at ACR meetings in the past 2 years was $44.9 \%$. The ACR had female representation above the mean compared with major North American medical conferences held in 2017. This proportion is also comparable to the estimated US adult rheumatology workforce data from 2015. ${ }^{3}$ However, there remains a gender gap across most medical specialties in Canada and the USA despite the current gender parity in medical school. Limited numbers of role models, sponsors and mentors may cause and perpetuate the problem. Although the gender gap at recent ACR meetings was narrower as compared with other conferences, we must remain cognizant of its presence and continue to work towards equal representation.

Kanika Monga, ${ }^{1}$ Jean Liew $\circledast^{2}$

${ }^{1}$ Rheumatology, University of Texas Health Science Center at Houston, Houston, Texas, USA

${ }^{2}$ Medicine, Division of Rheumatology, University of Washington, Seattle, Washington, USA

Correspondence to Dr Jean Liew, Medicine, Division of Rheumatology, University of Washington, Seattle,WA 98195-7230, USA; liew.jw@gmail.com

Twitter Kanika Monga @DrKanikaMonga and Jean Liew @rheum_cat

Contributors Both authors contributed equally to this work. Both were involved in study design, data collection, data analysis and drafting the manuscript.

Funding The authors have not declared a specific grant for this research from any funding agency in the public, commercial or not-for-profit sectors.

Competing interests None declared.

Patient and public involvement Patients and/or the public were not involved in the design, or conduct, or reporting, or dissemination plans of this research.

Patient consent for publication Not required.

Provenance and peer review Not commissioned; internally peer reviewed. (C) Author(s) (or their employer(s)) 2020. No commercial re-use. See rights and permissions. Published by BMJ.

\section{Check for updates}

To cite Monga K, Liew J. Ann Rheum Dis Epub ahead of print: [please include Day Month Year]. doi:10.1136/annrheumdis-2020-217673

Received 21 April 2020

Accepted 23 April 2020

Ann Rheum Dis 2020;0:1. doi:10.1136/annrheumdis-2020-217673

ORCID iD

Jean Liew http://orcid.org/0000-0002-8104-2450

\section{REFERENCES}

1 Adami G, Benini C, Vantaggiato E, et al. Gender disparity in authorship of guidelines and recommendations in rheumatology. Ann Rheum Dis:annrheumdis-2020-217119.

2 Ruzycki SM, Fletcher S, Earp M, et al. Trends in the proportion of female speakers at medical conferences in the United States and in Canada, 2007 to 2017. JAMA.

3 Battafarano DF, Ditmyer M, Bolster MB, et al. American College of rheumatology workforce study: supply and demand projections of adult rheumatology workforce, 2015-2030. Arthritis Care Res 2015;2018:617-26. 